\title{
Rate control algorithm for real-time applications of the multiview extension of H.264/AVC video coding standard
}

\author{
Hanieh Hosseini ${ }^{1}$ and Mehdi Rezaei ${ }^{2}$ \\ ${ }^{1}$ University of Sistan and Baluchistan Faculty of Engineering \\ ${ }^{2}$ Affiliation not available
}

July 21, 2020

\begin{abstract}
In this work, we propose a rate control algorithm (RCA) which regards characteristics of multiview video coding (MVC). The proposed RCA is designed for real-time applications of MVC and optimized to provide high quality compressed video bit streams with optimal utilization of channel bandwidth and buffering delay. The proposed RCA uses a fuzzy rate controller and a deterministic quality controller to define a quantization parameter (QP) for a Group of Pictures (GOP) based on given target rate, buffer, and quality constraints. The Key point in the proposed algorithm is to provide a variable bit rate multiview video bit stream with minimum fluctuations in QP and thereafter in quality while the buffer constraints are satisfied. The experimental results show that it can control the bitrate of all views according to the specified target bit rates for each view while the buffering constraints are completely obeyed and it provides compressed video bit streams with high visual quality.
\end{abstract}

\section{Hosted file}

Final revise.docx available at https://authorea.com/users/344751/articles/471311-ratecontrol-algorithm-for-real-time-applications-of-the-multiview-extension-of-h-264-avcvideo-coding-standard

\section{Hosted file}

Figures.docx available at https://authorea.com/users/344751/articles/471311-rate-controlalgorithm-for-real-time-applications-of-the-multiview-extension-of-h-264-avc-videocoding-standard

\section{Hosted file}

Tables.docx available at https://authorea.com/users/344751/articles/471311-rate-controlalgorithm-for-real-time-applications-of-the-multiview-extension-of-h-264-avc-videocoding-standard 